\title{
BMJ Open Neurophysiological correlates of motor planning and movement initiation in ACL-reconstructed individuals: a case- control study
}

\author{
Florian Giesche, Tobias Engeroff, Jan Wilke, Daniel Niederer, Lutz Vogt, \\ Winfried Banzer
}

To cite: Giesche F,

Engeroff T, Wilke J, et al. Neurophysiological correlates of motor planning and movement initiation in ACLreconstructed individuals: a case-control study. BMJ Open 2018;8:e023048. doi:10.1136/ bmjopen-2018-023048

- Prepublication history and additional material for this paper are available online. To view please visit the journal (http:// dx.doi.org/10.1136/bmjopen2018-023048).

Received 23 March 2018 Revised 23 July 2018 Accepted 20 August 2018

\section{Check for updates}

(c) Author(s) (or their employer(s)) 2018. Re-use permitted under CC BY-NC. No commercial re-use. See rights and permissions. Published by BMJ.

Department of Sports Medicine, Goethe University Frankfurt, Frankfurt, Germany

Correspondence to Mr Florian Giesche; giesche@sport.uni-frankfurt.de

\section{ABSTRACT}

Introduction Current evidence suggests that the loss of mechanoreceptors after anterior cruciate ligament (ACL) tears might be compensated by increased cortical motor planning. This occupation of cerebral resources may limit the potential to quickly adapt movements to unforeseen external stimuli in the athletic environment. To date, studies investigating such neural alterations during movement focused on simple, anticipated tasks with low ecological validity. This trial, therefore, aims to investigate the cortical and biomechanical processes associated with more sport-related and injury-related movements in ACLreconstructed individuals.

Methods and analysis ACL-reconstructed participants and uninjured controls will perform repetitive countermovement jumps with single leg landings. Two different conditions are to be completed: anticipated $(n=35)$ versus unanticipated $(n=35)$ successful landings. Under the anticipated condition, participants receive the visual information depicting the requested landing leg prior to the jump. In the unanticipated condition, this information will be provided only about $400 \mathrm{msec}$ prior to landing. Neural correlates of motor planning will be measured using electroencephalography. In detail, movement-related cortical potentials, frequency spectral power and functional connectivity will be assessed. Biomechanical landing quality will be captured via a capacitive force plate. Calculated parameters encompass time to stabilisation, vertical peak ground reaction force, and centre of pressure path length. Potential systematic differences between ACL-reconstructed individuals and controls will be identified in dependence of jumping condition (anticipated/ unanticipated, injured/uninjured leg and controls) by using interference statistics. Potential associations between the cortical and biomechanical measures will be calculated by means of correlation analysis. In case of statistical significance $(\alpha<0.05$.) further confounders (cofactors) will be considered.

Ethics and dissemination The independent Ethics Committee of the University of Frankfurt (Faculty of Psychology and Sports Sciences) approved the study. Publications in peer-reviewed journals are planned. The findings will be presented at scientific conferences.

Trial status At the time of submission of this manuscript, recruitment is ongoing.

Trial registration number NCT03336060; Pre-results.
Strengths and limitations of this study

- First-time investigation of the link between electrocortical (EEG) activity (neural correlates of motor planning) and biomechanical function during typical sport-related and injury-related movements (single leg landings) in anterior cruciate ligament (ACL)reconstructed individuals.

- Association between increased use of motor planning capacities and lower postural control during landing in ACL-reconstructed individuals may have major implications for rehabilitation and return to sports.

- Comparison against both, unaffected leg of the ACLreconstructed individuals as well as uninjured controls and rigorous control of relevant confounders (i.e. cognitive functions).

Investigator and participant blinding is not possible.

\section{INTRODUCTION}

Anterior cruciate ligament (ACL) tears of the knee represent one of the most common sports-related injuries, particularly among young, physically active individuals. ${ }^{1}{ }^{2}$ The disorder represents the leading cause of sports-related surgery ${ }^{3}$ and, besides the severe acute and long-term consequences (eg, pain, functional disability and impairements ${ }^{4}$ ), is associated with a higher lifetime risk of knee osteoarthritis. ${ }^{5}$ Despite several multidisciplinary therapeutic approaches aiming to restore preinjury neuromuscular function, the odds of sustaining a second tear are significantly increased in afflicted individuals who returned to sports. ${ }^{6} 7$ It may, therefore, be inferred that current rehabilitation paradigms fail to eliminate all impairments of the injury. ${ }^{89}$

Besides affecting mechanical stability, ACL rupture is associated with substantial destructions of ligament mechanoreceptors. ${ }^{10}$ Under healthy conditions, the sensory 


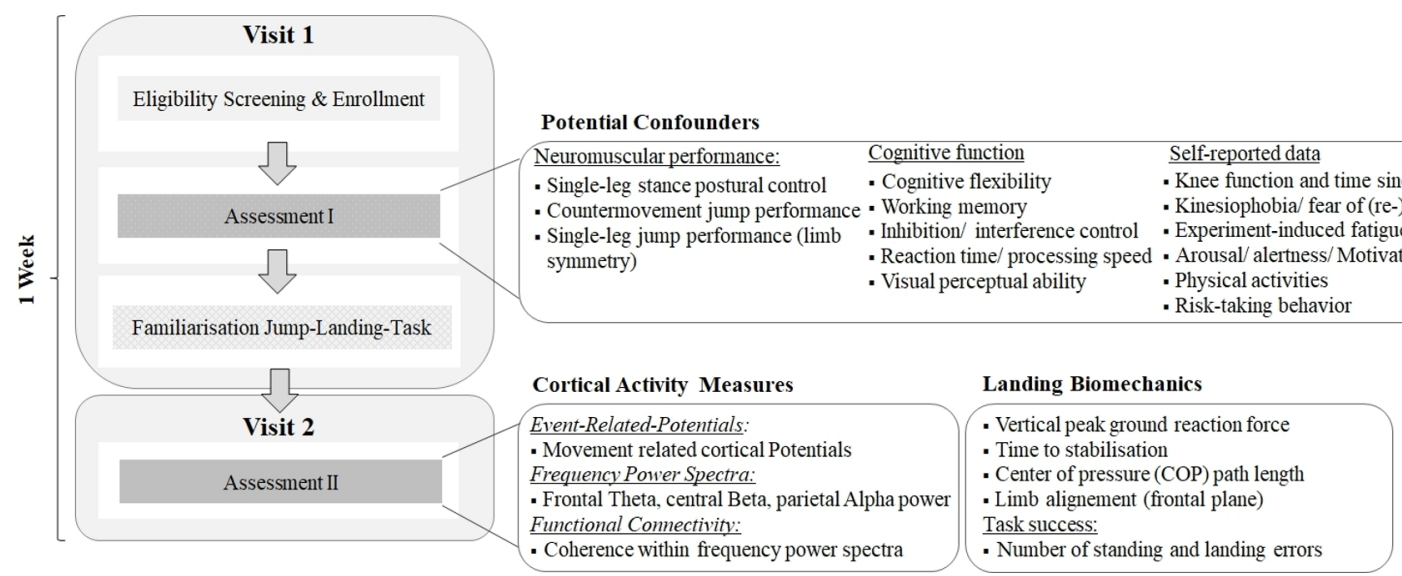

Figure 1 Experimental study setup. The figure details the days in which participants are assessed.

receptors located in the ACL, for example, Ruffini and Pacini corpuscles, provide essential proprioceptive information ${ }^{11-13}$ and regulate the activity of the hamstring muscles. ${ }^{14-16}$ Representing a synergist of the ACL, the hamstrings are paramount for functional stability of the knee joint. ${ }^{1718}$ As the neural drive to the muscle depends on the sensory input, the above described peripheral deafferentation (mechanoreceptor damage), secondary to the rather acute consequences of the injury (eg, pain, swelling and inflammation), could induce neuroplastic changes in the brain. ${ }^{192} 20$

Current evidence demonstrates persistent central nervous system adaptations occurring after ligamentous injuries and subsequent reconstruction surgeries. ${ }^{21}$ Electroencephalographic (EEG) studies revealed increased activity of the frontal ${ }^{22}$ and frontoparietal cortex ${ }^{23}$ during the execution of sensorimotor tasks in ACL-reconstructed individuals compared with unimpaired controls. It has been suggested that this may be related to an increased attentional control and somatosensory information processing related to a higher working memory load. ${ }^{22} 23$ Similarly, neuroimaging studies showed ACL-injured individuals to exhibit a higher recruitment of cortical areas responsible for motor planning, sensory processing and visual motor control during the execution of repetitive knee extensions. ${ }^{24}{ }^{25}$ It may be concluded that the brain of ACL-injured and ACL-reconstructed individuals relies more on higher order motor control areas ${ }^{26}$ and executive function even during simple, feedback-controlled movements, such as joint repositioning, ${ }^{23}$ force matching tasks $^{22}$ and knee extensions ${ }^{825}$ in order to compensate for the reduced sensory input. ${ }^{21} 2527$

While the consequences of this supraspinal compensation strategy may be invisible during activities of daily living, they may place an athlete at risk of injury during sports and competition. To maintain neuromuscular control in a complex and dynamic athletic environment, a constant interaction between intrinsic (eg, motor planning, joint position and movement) and extrinsic factors (eg, other players, ball and unanticipated stimuli) is required, based on the simultaneous integration and processing of varying proprioceptive, visual and vestibular information. ${ }^{828-30} \mathrm{In}$ most situations leading to an injury, athletes, under high time constraints, are required to quickly adapt to the changing environment and cannot rely on preplanned, anticipated movements exclusively. ${ }^{28}{ }^{29}$ Against this background, current evidence suggests that rapid movement adaptations such as single leg landings and side-cuttings in response to an unanticipated visual stimulus induce aberrant knee kinematics and kinetics that may increase the risk of injury. ${ }^{31}$

To date, studies investigating the cortical alterations during movement of ACL patients focused on simple, anticipated tasks mainly requiring feedback control and assesses in sitting or lying position. ${ }^{22-25}$ Such tasks have low ecological validity as they mimic sport-specific movement characteristics only to a limited degree. Our planned trial, therefore, aims to gain further insight into the cortical and biomechanical processes associated with anticipated/preplanned versus unanticipated/unforeseen single leg jump landings in ACL-reconstructed individuals and healthy controls. Specifically, the hypothesis will be tested that ACL-reconstructed individuals compared with control individuals exhibit increased cortical motor planning prior jumping. Furthermore, we assume that this higher use of cerebral resources will be associated with a lower landing quality in ACL-reconstructed individuals.

\section{METHODS}

\section{Study design and ethical standard}

An explorative case-control study will be conducted. All participants provide written informed consent. The study has been prospectively registered at Clinicaltrials.gov (NCT03336060).

\section{Study setup}

After study enrolment, each individual will be scheduled for two visits within 1 week (figure 1). At visit 1 , potential confounders (for details see Potential confounders below) are assessed. Subsequently, participants will be familiarised with the anticipated and unanticipated jump-landing tasks of the study. At visit 2, the main measurements are 


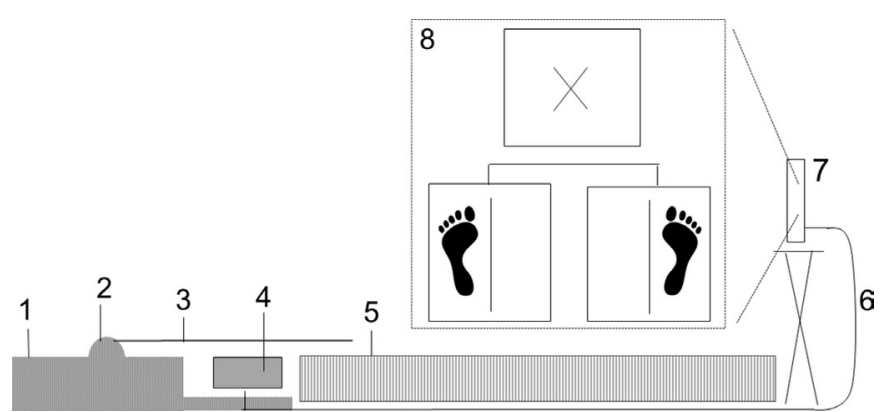

Figure 2 Setup of the jump-landing experiment. Rubber mat (1); hinge (2); plastic panel (3); USB button switch (4); force plate (5); USB cable connecting button switch with screen (PowerPoint) (6); laptop with screen (17-nch diameter) (7); PowerPoint slides demonstrated on laptop screen indicating left or right foot landing (randomised order). Before each foot slide a separate slide containing a fixation cross is demonstrated (8).

performed. Both visits will take place at comparable time of day.

\section{Sample}

Recruited participants will be ACL-reconstructed individuals (cases) and healthy, uninjured individuals (controls). All participants will be recruited at local physical rehabilitation centres, physiotherapists and medical practices, sports clubs, fitness centres and the local university's sports campus by means of flyers, emails and personal addressing. Inclusion criteria for all participants are: (1) male sex, (2) age between 20 years and 40 years, and (3) engagement in regular physical activity. Cases will be included if they have a history of unilateral ACL rupture with reconstruction surgery ( $>1$ year), irrespective of the graft used for reconstruction and surgical procedure, and full clearance to return to sport provided by the treated physician. The following exclusion criteria will be applied:

- Exorbitant concomitant knee injury (ie, bone bruise grade 3 or 4 , full-thickness articular cartilage lesion larger than $1 \mathrm{~cm}^{2}$ and 'unhappy triad') (cases).

- Previous ACL injury or surgery of the uninvolved knee (cases).

- Life-quality impairing somatic/psychological diseases/disorders (all participants).

- Acute or chronic inflammation/disorders/pain of the musculoskeletal system (all participants).

- Medication modifying pain perception and proprioception (all participants).

- Muscle soreness (all participants).

- Any severe musculoskeletal injury of the lower limb (controls).

- History of head injuries (ie, concussions, all participants).

\section{Patient and public involvement}

Patients will be not involved in this study. We only include ACL-reconstructed individuals (minimum 1 year after surgery) who have returned to their initial daily, physical and sportive activities and have restored their neuromuscular performance of the injured lower leg indicated by a side symmetry of single leg hop for distance testing above 85 percent. Achieving a ratio of at least 85 percent is recommended before return to unrestricted sport activities $^{32}$ as a lower limb symmetry increases the risk for reinjury. ${ }^{33}$

\section{Experimental approach}

All participants will perform repetitive countermovement jumps (hands placed at the hip) with single leg landings. Two different conditions are to be completed: anticipated versus unanticipated landings. For the anticipated condition, the participants receive a visual information depicting the requested landing leg prior to the jump. In the unanticipated condition, this information will be provided only after take-off. After a brief standardised warm-up (30 jumping jacks) and three test jumps, all participants have to perform a total of 70 successful jumps ( $n=35$ per condition), using the above described paradigm. Pilot data indicated that a number of 35 successful trials per condition ( $5 \mathrm{~min}$ breaks in sitting position after each 14 trials) are sufficient in order to produce stable results (neural correlates of motor planning; EEG) without evoking measurable exhaustion in any assessed parameter.

The indication of the requested landing leg will be delivered by means of a laptop screen (17-inch diameter). It is positioned at $2.5 \mathrm{~m}$ distance in front of the participants (figure 2). On the screen, a slide (Microsoft PowerPoint 2010) with a left or right footprint located on the left or right side of a vertical line is shown (figure 2).

In anticipated trials, the slide indicating the landing leg will be presented constantly before take-off (for details, refer to figure 3 ).

For the unanticipated trials, a single button USB switch (KKmoon; South Africa) connected to the laptop will be used in order to elicit a slide change ( $120 \mathrm{~ms}$ delay) from the fixation cross to the landing leg slide upon take-off (for details, refer to figure 4; online supplementary file - video).

A successful jump is defined as holding a stable landing position for at least $10 \mathrm{sec}$. The participants will be allowed to use their arms to equilibrate the postural sway immediately after landing. After landing, their hands need to be repositioned on the hip while focusing a cross on the wall at eye level. Unsuccessful trials are categorised as standing errors (touching the ground with the free leg, leaving the force plate and touching the ground with the hands, and falls) and/or landing errors (landing on the wrong foot or both foot). To prevent excessive exhaustion during the experiment, the 70 jumps will be stratified into blocks of 14 with 5 min rests (sitting position) in between. Randomised selection of the jump conditions will be performed using BIAS for windows (University Frankfurt, Germany, V.11.06).

Previous pilot testing revealed longer flight times for unanticipated jump-landings compared with anticipated landings. Therefore, two strategies will be used to ensure 


\section{Anticipated}

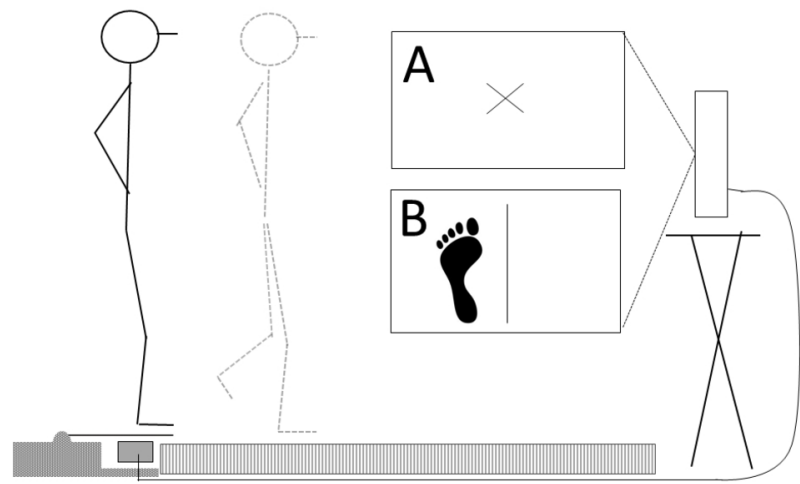

Figure 3 Proceedings of anticipated jump-landings and the clarification when and how the visual stimulus indicating the side on which the single leg landing has to be performed is presented. $A=$ slide with a fixation cross; $B=$ slide is presented before the initiation of the jump. Participants start standing in bipedal position on the plastic panel (3; figure 2) while fixating the cross (A). The experimenter indicates the start of movement preparation by mentioning the condition 'anticipated'. Simultaneously, the slide demonstrating the landing leg $(B)$ is shown. Afterwards, participants initiate the jump by their own.

uniform flight durations between the two disposed conditions. First, during the familiarisation session, the participants will be trained to constantly achieve comparable flight times of 480-520 msec regardless of the jump condition. This duration, corresponding to a jumping height of about $30 \mathrm{~cm}$, was chosen because the button switch has a latency of $120 \mathrm{msec}$ from release to slide appearance and because other similar trials have used flight times of 400 msec. $^{3435}$ Second, in addition to the task familiarisation, during the breaks of the actual experiment, the participants will be provided with feedback regarding the achieved flight heights. All participants are required to wear sports clothes (t-shirt and shorts) and indoor sports shoes during both task familiarisation session and the actual jump landing experiment.

\section{Measurements}

Cortical measures of motor planning and preparation serve as the main outcome of the trial. They were assessed prior to jumping. To ensure self-initiated movements the start of the jump is not triggered to an external stimulus in both jump-landing conditions. To reduce artefacts generated by eye movements, participants are asked to fixate the cross (figures 3 and 4) shown on the laptop screen prior to jumping.

\section{Cortical activity}

Brain activity prior to jump movement initiation will be captured using a 32-channel EEG system with a wireless amplifier (LiveAmp, BrainProducts, Gilching, Germany). The device samples data at a frequency of $500 \mathrm{~Hz}$ (24-bit analogue-to-digital) and has an integrated three-axis acceleration sensor (measurement range: $\pm 2 \mathrm{~g}$,

\section{Unanticipated}

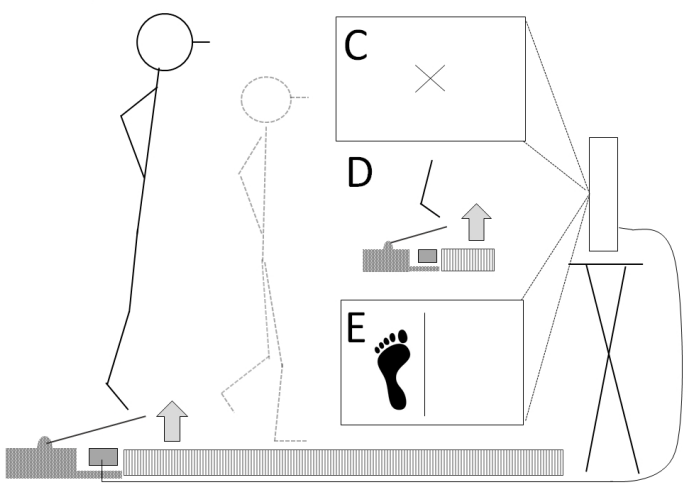

Figure 4 Proceedings of unanticipated jump-landings and the clarification when and how the visual stimulus indicating the side on which the single leg landing has to be performed is presented. $\mathrm{C}=$ slide with a fixation cross (same as in A; figure 3); D=USB button (4, figure 2) release during take-off (plastic panel elevates) initiating slide change; $\mathrm{E}=$ slide indicating the landing foot presented only after take-off. Participants start standing in bipedal position on the plastic panel (3; figure 2) while fixating the cross (C). The experimenter mentions the jump-landing condition 'unanticipated'. Afterwards, participants will initiate the jump by their own while $C$ is still shown. The slide indicating the landing leg (E) appears about $120 \mathrm{msec}$ after take-off (button release; D) and is than shown continuously (for more details, refer to the online supplementary video file).

resolution: $1 \mathrm{mg} /$ bit, 12 bit; error: $\pm 200 \mathrm{~g}$ ). It is carried in a custom-made backpack (700 g), which is attached to the upper back of the participants. It is equipped with a power bank to guarantee permanent power supply of the amplifier (200 g). Positioning of the active slim electrodes embedded in the EEG cap (actiCAP, Easycap, Herrsching, Germany) will be performed according to the 10-20 international system. ${ }^{36}$ Impedance will be kept below $5 \mathrm{k}$, and no online filters will be applied.

The EEG signal will be recorded throughout the whole jump landing experiment. In addition, EEG data will be collected during $2 \mathrm{~min}$ sitting rests prior to and after the 70 successful jumps. To reduce artefacts resulting from eye movements during these measurements, the participants will be instructed to fixate a cross, which is displayed on the laptop screen.

Three EEG parameters will be analysed: movement-related cortical potentials (MRCPs), frequency power spectra and functional connectivity. The MRCPs occur about 2 sec prior to voluntary movements and can be subdivided into successive three parts that will be assessed in the planned trial: bereitschaftspotential—negative slope-motor potential ${ }^{3738}$ (for a review, see ref 39). The bereitschaftspotential (BP) is a slowly rising, bilateral negativity, generated in the supplementary and presupplementary motor area ( 1.5 to $0.5 \mathrm{sec}$ before movement onset $\left.{ }^{4041}\right)$. Subsequently, a steeper negativity, the negative slope occurs and relates to the activity of the contralateral primary motor cortex (starting about $0.5 \mathrm{sec}$ prior to movement onset ${ }^{38} 42$ ). Both signals 
are followed by the motor potential, ${ }^{41}$ the peak negativity corresponding to the movement onset itself. ${ }^{43} 44$ MCRPs are thought to reflect the motor cortical involvement during motor planning and preparing of a self-initiated movement. ${ }^{42}$ For each of the MRCP measures, acceptable test-retest reliability has been reported. ${ }^{45}$

To investigate the attentional and working memory processes needed for initiating and executing the jumps different frequency power spectra (theta, beta and alpha) will be captured for frontal, central and parietal brain areas. Theta power will be measured in the frontal cortex and increases with higher levels of focused attention. ${ }^{46}$ Alpha-2 power, inversely related to the activation ${ }^{47}$ of the underlying somatosensory cortex, decreases with higher demands of sensory information processing during sensorimotor tasks. ${ }^{23}$ Both frontal theta and parietal alpha-2 have been shown to be strongly associated with working memory load. ${ }^{48}$ It is, furthermore, well known that the planning and preparation of voluntary movements are accompanied by an event-related desynchronisation ${ }^{49} 50$ of the alpha and beta (including sensorimotor rhythm ${ }^{51}$ ) frequencies power corresponding to the parietal and sensorimotor areas. ${ }^{52-56}$ EEG power measures have been demonstrated to be highly reliable during both rest $^{57}$ and sensorimotor tasks. ${ }^{58}$

Coherence analyses will be applied to examine the functional connectivity between the brain region specific coworking processes (motor planning areas; frontoparietal network ${ }^{48}$ ). Following the approach of Sauseng $e t a l^{48}$ and Silva $e t a l^{59}$ coherence analysis will be conducted for the above-mentioned frequency bands (eg, theta, beta and alpha). The test-retest reliability of coherence testing has been shown to be sufficient to high for most brain areas and frequency bands. ${ }^{60}$

\section{Biomechanical parameters}

A capacitive force measurement platform $(50 \mathrm{~Hz}$, Zebris FDM, Zebris Medical GmbH, Isny, Germany) will be used to assess postural stability following the single leg landings. Three parameters will be investigated: time to stabilisation (TTS), vertical peak ground reaction force (GRF) and centre of pressure (COP) path length. TTS describes the capacity to regain a stable stance as quickly as possible. It will be computed according to Colby et $a f^{61}$ and Wikstrom et al. ${ }^{62}$ Here, the dynamic cumulative average weight is calculated, based on the continuous force plate recordings until 10 sec after landing. A stable stance is assumed as soon as the sequential average no longer exceeds the threshold of $0.25 \mathrm{SD}$ of the overall mean ground vertical force. The TTS has been demonstrated to exhibit moderate to high reliability ${ }^{63}$ Vertical peak GRF is the maximal vertical force impact on landing. Using the raw data, the highest value (Newton) will be identified. COP path length represents the absolute cumulative sway of the total covered distance by the COP during the trial duration. ${ }^{64}$ The path length will be assessed up until $2.5 \mathrm{sec}$ after the initial ground contact, which corresponds to the duration of the early dynamic landing phase. ${ }^{65}$ In terms of balance assessment,
COP measures have been demonstrated satisfactory reliability ${ }^{66}$ Intraindividual mean values will be calculated for TTS, peak GRF and COP path length in dependence of the disposed conditions.

\section{Potential confounders}

The following parameters, potentially affecting the biomechanical and cortical outcomes, will be assessed and analysed for their confounding influence:

- Dynamic stability feed-forward performance of the lower limb (single leg hop for distance ${ }^{67}$ ).

- Postural control during single leg stance (capacitive force measurement plate Zebris PDMS, Zebris, Isny, Germany).

- Limb alignment in frontal plane evaluated by using Single-Leg Landing Error Scoring System. ${ }^{68}$

- Cognitive function (visuoperceptual abilities - Trail Making Test $\mathrm{A}^{69}$; simple/choice reaction speed Detection/Identification Task ${ }^{70}$; working memory - verbal digit span test ${ }^{71}$; spatial working memory/ learning efficiency - Groton Maze Learning Test ${ }^{72}$; cognitive flexibility - trail making test $\mathrm{B}^{69}$; response inhibition - stop-signal-task ${ }^{73}$; response interference control - Stroop Colour-Word task ${ }^{74}$ ).

- Current and former physical/sports activities (ie, primary sport, frequency/duration per week, performance level and years of experience).

- Self-reported knee function (Lysholm Knee Score Scale $^{75}$ ).

- Self-reported perceived fatigue of the lower limbs $(10 \mathrm{~cm}$ visual analogue scale (VAS) $)$.

- Kinesiophobia, or fear of movement/ (re-)injury (Tampa Scale for Kinesiophobia ${ }^{76}$ ).

- Task-specific fear of movement/reinjury $(10 \mathrm{~cm}$ VAS).

- Level of arousal and alertness (10 cm VAS).

- Risk-taking behaviour (domain-specific risk-taking/ DOSPERT scale ${ }^{77}$ ).

\section{EEG data processing}

All EEG data will be filtered with a Butterworth high-pass filter of $0.001 \mathrm{~Hz}(24 \mathrm{~dB} /$ octave) and a low-pass filter of $40 \mathrm{~Hz}(24 \mathrm{~dB} /$ octave). For movement onset detection, the accelerometer data of the amplifier are used. In each jump trial, the EEG signals will be segmented into epochs of $2500 \mathrm{msec}$, from $2.000 \mathrm{msec}$ before to 500 msec after movement onset. Components that are associated with eye movements and blinks will be removed by using independent component analysis according to Winkler et al. ${ }^{78}$ Artefact removal will be applied according to the criteria used by Saliasi $e t a l^{79}$ by using automated artefact rejection. Afterwards, all segments will be also visually inspected and trials with remaining artefacts (ie, eye blinks and movement artefact) will be removed. Only artefact-free trials will be used for analysis.

Time-domain specific analysis will be conducted to investigate the MRCP prior each jump. According to Spring et $a l,{ }^{43} \mathrm{MRCP}$ will be divided into three successive epochs as follows: the bereitschaftspotential divided in an 
early (BP-1: $-1.500 \mathrm{msec}$ to $-1.000 \mathrm{msec}$ ) and late component (BP-2: $-1.000 \mathrm{msec}$ to $-500 \mathrm{msec}$ ) and the negative slope component ( $-500 \mathrm{msec}$ to $0 \mathrm{msec})$, including the motor potential. The mean and peak activity as well as onset time of the MRCP will be calculated primarily for the fronto-central (FC1 and FC2) and central electrodes $(\mathrm{C} 3, \mathrm{Cz}$ and $\mathrm{C} 4)$ as these channels correspond mainly to the supplementary and primary motor areas.

Frequency domain (spectral) analysis will be conducted by means of fast Fourier transformation dividing artefact-free epochs into the frequency power spectra for both measurement at rest (continuous EEG) and during the jump landing experiment. For the latter, in terms of time-frequency analysis, the $1.5 \mathrm{sec}$ EEG prior to movement onset will be separated into three successive $0.5 \mathrm{sec}$ epochs: $-1.500 \mathrm{msec}$ to -1.000 msec (T1) $-1.000 \mathrm{msec}$ to $-500 \mathrm{msec}$ (T2) and -500 msecto 0 msec (T3). According to the literature, the mean frequency power will be mainly analysed for the frontal theta $\left(\mathrm{Fz}^{80}\right)$, central beta $(\mathrm{C} 3, \mathrm{Cz}$ and $\mathrm{C} 4)$ and parietal alpha-2 (P3, Pz and $\mathrm{P} 4)$. Finally, to examine functional connectivity, coherence analysis in the respective frequency bands will be applied. ${ }^{81}$ All electrocortical outcomes will be calculated for each condition (anticipated/unanticipated, injured/uninjured leg and controls). The EEG at rest measurements will be considered as control condition. All EEG data processing will be applied by using the BrainVision Analyzer software (Brain Products, Gilching, Germany).

\section{Statistics}

All calculations will be performed after checking the underlying assumptions for parametric or non-parametric testing (Shapiro-Wilk normality test for testing of normal distribution, while Levene test for variance homogeneity testing). The EEG outcome measures will be transformed to normalise distributions by using logarithmic based or arcsine transformation, if indicated. Data will be reported descriptively as means, SD and 95\% CIs. Potential systematic differences between cases and controls (between-subject factors) and within both groups (within-subject factors) will be identified in dependence of jumping condition (anticipated/unanticipated, injured/ uninjured and controls) by using interference statistics. The relationships between the cortical activity and biomechanical measures will be analysed by means of correlation analyses. The influence of the potential confounders on cortical and biomechanical outcomes during the jump landing task will be determined by correlation analysis likewise. If statistical associations occur, significant confounders will be considered by means of cofactor analysis. To maintain homogeneity, participants of both groups will be matched based on age, jump performance and their current physical/sports activities (open vs closed skill sports) ${ }^{82}$

The level of statistical significance is set to $\alpha<0.05$. Based on the exploratory nature of this study, no alpha-error adjustment will be performed for multiple hypotheses testing. Microsoft Excel 2010 for Windows and SPSS Statistics (V.24.0) will be used for statistical data analysis.

\section{DISCUSSION}

To the best of our knowledge, the planned study is the first to explore both, the cortical and biomechanical fundamentals underlying unanticipated single leg landings in ACL-reconstructed individuals. Hence, this study will provide the first evidence of the neural mechanism of motor planning associated with sport-relavant and injury-relevant movement affordances.

Another strength of our design consists in the standardised assessment of relevant confounders potentially influencing the chosen outcomes. This, particularly, relates to cognitive functions, which have been identified to be associated with athletic performance (eg, ball game sports $^{8384}$ ) as well as knee injury risk ${ }^{85}$ and incidence. ${ }^{86-88}$

Our study will reveal results relevant for practice. If the hypothesised association between increased use of motor planning capacities and lower postural control during landing are verified, this would have major implications for rehabilitation. Three key aspects may be of particular relevance: above all (1), an increased reliance on motor planning during athletic high-risk situations could represent a new factor predisposing for ACL (re-)injury. Future prospective observational studies may therefore include unanticipated jump-landing tasks in order to elucidate its value in predicting injury and monitoring the return to play/return to sports process.

Another issue (2) relates to the elaboration of new training approaches. In addition to physical exercise, for example, dynamic balance, dual/multitask training approaches (including external focus) and visual motor exercise paradigms, ${ }^{8}$ electrophysiological methods, such as neuromuscular electrical stimulation, ${ }^{89}$ transcutaneous electrical nerve stimulation, ${ }^{90}$ electromyography biofeedback ${ }^{91}$ and transcranial magnet stimulation, ${ }^{92}$ may represent intriguing options to restore somatosensory function and quadriceps corticomotor excitability of ACL-reconstructed individuals. Their application may open new therapeutic avenues, if changes in motor planning prior to unanticipated jump landings could be evidenced in the cases.

Finally (3), affordable devices for daily practice would be needed to assess an individuals' ability to react and properly adjust his motor plan to an unforeseen/unanticipated external visual stimulus.

Despite the promising approach, some limitations have to be taken into account. No investigator nor participant blinding is possible using a quasiexperimental approach. Moreover, the neural correlates of motor planning are only detectable prior to the jump, but not after take-off due to serious EEG artefacts caused by the jump. Female athletes are at higher risk for non-contact ACL injuries compared with their male counterparts. ${ }^{93} 94$ To exclude the influences due to this variable, only participants of one sex will be considered for inclusion. Males are chosen because pilot 
testing indicated that those were more likely to achieve the required jump height. The study results will refer to successful landings only. However, unsuccessful trials (i.e. landing errors) may provide additional information in terms of predicting injury risk. It could therefore be useful to investigate if cortical activities differ between successful and unsuccessful trials. This would certainly require a considerable increase of the total number of jump landings in order to obtain a sufficient amount of error trials for EEG analysis. Due to the considerably increased risk of fatigue and a greater effort for the participants resulting from this, adaptions to the described paradigm may be the second step and should be performed after proving the feasibility of the current approach.

Acknowledgements We especially recognize the assistance of Dr Solveig Vieluf (Sports Medicine Department, University of Paderborn, Germany) in the development of the EEG setup. Furthermore, we would like to thank Alwin Eifler for providing written consent for publication of his individual details and the accompanying video of this manuscript.

Contributors FG developed the jump-landing setup and selected the neurophysiological and biomechanical outcome measures. FG wrote the first draft of the manuscript, revised the manuscript and provided final approval. TE assisted FG in the development of the trial jump-landing setup and in the selection of biomechanical outcome parameters. TE revised the manuscript, provided critical review and final approval. JW assisted FG in the development of the trial jump-landing setup and in the selection of biomechanical outcome parameters. JW revised the manuscript, provided critical review and final approval. DN revised the manuscript, provided critical review and final approval. LV revised the manuscript and provided intellectual contributions to the final, submitted version of the manuscript. WB revised the manuscript and provided intellectual contributions to the final, submitted version of the manuscript. The material within has not been and will not be submitted for publication elsewhere except as an abstract. The authors agree that the copyright for our article is transferred to the publisher if and when the article is accepted for publication.

Funding This research received no specific grant from any funding agency in the public, commercial or not-for-profit sectors.

Competing interests None declared.

Patient consent Not required.

Ethics approval The study was approved by the local Ethics Committee of the Faculty of Psychology and Sport Science, Goethe-University Frankfurt (reference number: 2017/27). The trial will be carried out according to the Guidelines for Good Clinical Practice and according to the Declaration of Helsinki, including its modification of Fortaleza.

Provenance and peer review Not commissioned; externally peer reviewed.

Open access This is an open access article distributed in accordance with the Creative Commons Attribution Non Commercial (CC BY-NC 4.0) license, which permits others to distribute, remix, adapt, build upon this work non-commercially, and license their derivative works on different terms, provided the original work is properly cited, appropriate credit is given, any changes made indicated, and the use is non-commercial. See: http://creativecommons.org/licenses/by-nc/4.0/.

\section{REFERENCES}

1. Arna Risberg M, Lewek M, Snyder-Mackler L. A systematic review of evidence for anterior cruciate ligament rehabilitation: how much and what type? Physical Therapy in Sport 2004;5:125-45.

2. Spindler KP, Wright RW. Clinical practice. Anterior cruciate ligament tear. N Engl J Med 2008;359:2135-42.

3. Joseph AM, Collins CL, Henke NM, et al. A multisport epidemiologic comparison of anterior cruciate ligament injuries in high school athletics. J Athl Train 2013;48:810-7.

4. Risberg MA, Holm I, Tjomsland O, et al. Prospective study of changes in impairments and disabilities after anterior cruciate ligament reconstruction. J Orthop Sports Phys Ther 1999;29:400-12.
5. Khan T, Alvand A, Prieto-Alhambra D, et al. ACL and meniscal injuries increase the risk of primary total knee replacement for osteoarthritis: a matched case-control study using the Clinical Practice Research Datalink (CPRD). Br J Sports Med 2018, doi: 10.1136/bjsports-2017-097762. [Epub ahead of print 13 Jan 2018]

6. Paterno MV, Rauh MJ, Schmitt LC, et al. Incidence of Second ACL Injuries 2 years after primary acl reconstruction and return to sport. Am J Sports Med 2014;42:1567-73.

7. Wiggins AJ, Grandhi RK, Schneider DK, et al. Risk of Secondary Injury in Younger Athletes After Anterior Cruciate Ligament Reconstruction: A Systematic Review and Meta-analysis. Am J Sports Med 2016:44:1861-76.

8. Grooms D, Appelbaum G, Onate J. Neuroplasticity following anterior cruciate ligament injury: a framework for visual-motor training approaches in rehabilitation. J Orthop Sports Phys Ther 2015;45:381-93.

9. Pelletier R, Higgins J, Bourbonnais D. Is neuroplasticity in the central nervous system the missing link to our understanding of chronic musculoskeletal disorders? BMC Musculoskelet Disord 2015;16:25.

10. Dhillon MS, Bali K, Prabhakar S. Differences among mechanoreceptors in healthy and injured anterior cruciate ligaments and their clinical importance. Muscles Ligaments Tendons $J$ 2012;2:38-43.

11. Dhillon MS, Bali K, Prabhakar S. Proprioception in anterior cruciate ligament deficient knees and its relevance in anterior cruciate ligament reconstruction. Indian J Orthop 2011;45:294-300.

12. Schultz RA, Miller DC, Kerr CS, et al. Mechanoreceptors in human cruciate ligaments. A histological study. The Journal of Bone \& Joint Surgery 1984;66:1072-6.

13. Çabuk H, Kușku Çabuk F. Mechanoreceptors of the ligaments and tendons around the knee. Clinical Anatomy 2016;29:789-95.

14. Tsuda E, Okamura Y, Otsuka $\mathrm{H}$, et al. Direct evidence of the anterior cruciate ligament-hamstring reflex arc in humans. Am J Sports Med 2001;29:83-7.

15. Tsuda $E$, Ishibashi $Y$, Okamura $Y$, et al. Restoration of anterior cruciate ligament-hamstring reflex arc after anterior cruciate ligament reconstruction. Knee Surgery, Sports Traumatology, Arthroscopy 2003:11:63-7.

16. Beard DJ, Kyberd PJ, Fergusson CM, et al. Proprioception after rupture of the anterior cruciate ligament. An objective indication of the need for surgery? J Bone Joint Surg Br 1993;75-B:311-5.

17. Blackburn JT, Norcross MF, Padua DA. Influences of hamstring stiffness and strength on anterior knee joint stability. Clin Biomech 2011;26:278-83.

18. Solomonow M, Baratta $\mathrm{R}$, Zhou $\mathrm{BH}$, et al. The synergistic action of the anterior cruciate ligament and thigh muscles in maintaining joint stability. Am J Sports Med 1987;15:207-13.

19. Kapreli E, Athanasopoulos S. The anterior cruciate ligament deficiency as a model of brain plasticity. Med Hypotheses 2006;67:645-50.

20. Ward S, Pearce AJ, Pietrosimone B, et al. Neuromuscular deficits after peripheral joint injury: A neurophysiological hypothesis. Muscle Nerve 2015;51:327-32.

21. Needle AR, Lepley AS, Grooms DR. Central nervous system adaptation after ligamentous injury: a summary of theories, evidence, and clinical interpretation. Sports Medicine 2017:47:1271-88

22. Baumeister J, Reinecke K, Schubert M, et al. Altered electrocortical brain activity after ACL reconstruction during force control. $J$ Orthop Res 2011;29:1383-9.

23. Baumeister J, Reinecke K, Weiss M. Changed cortical activity after anterior cruciate ligament reconstruction in a joint position paradigm: an EEG study. Scand J Med Sci Sports 2008;18:473-84.

24. Grooms DR, Page SJ, Onate JA. Brain activation for knee movement measured days before second anterior cruciate ligament injury: neuroimaging in musculoskeletal medicine. J Athl Train 2015;50:1005-10.

25. Kapreli E, Athanasopoulos S, Gliatis J, et al. Anterior cruciate ligament deficiency causes brain plasticity: a functional MRI study. Am J Sports Med 2009;37:2419-26.

26. Ball T, Schreiber A, Feige B, et al. The role of higher-order motor areas in voluntary movement as revealed by high-resolution EEG and fMRI. Neuroimage 1999;10:682-94.

27. Needle AR, Rosen AB. Ligament injury changes brain function: now let's think about it.... Athletic Training \& Sports Health Care 2017:9:198-9.

28. Grooms DR, Onate JA. Neuroscience Application to Noncontact Anterior Cruciate Ligament Injury Prevention. Sports Health 2016;8:149-52.

29. Swanik CB. Brains and sprains: the brain's role in noncontact anterior cruciate ligament injuries. J Ath/ Train 2015;50:1100-2. 
30. Herman D, Zaremski JL, Vincent HK, et al. Effect of Neurocognition and concussion on musculoskeletal injury risk. Curr Sports Med Rep 2015;14:194-9.

31. Almonroeder TG, Garcia E, Kurt M. The effects of anticipation on the mechanics of the knee during single-leg cutting tasks: A systematic review. Int J Sports Phys Ther 2015;10:918-28.

32. Barber-Westin SD, Noyes FR. Factors used to determine return to unrestricted sports activities after anterior cruciate ligament reconstruction. Arthroscopy 2011;27:1697-705.

33. Kyritsis P, Bahr R, Landreau P, et al. Likelihood of ACL graft rupture: not meeting six clinical discharge criteria before return to sport is associated with a four times greater risk of rupture. $\mathrm{Br} J$ Sports Med 2016;50:946-51.

34. Brown TN, Palmieri-Smith RM, McLean SG. Sex and limb differences in hip and knee kinematics and kinetics during anticipated and unanticipated jump landings: implications for anterior cruciate ligament injury. Br J Sports Med 2009;43:1049-56.

35. McLean SG, Samorezov JE. Fatigue-induced ACL injury risk stems from a degradation in central control. Med Sci Sports Exerc 2009;41:1662-73.

36. Klem GH, Lüders $\mathrm{HO}$, Jasper $\mathrm{HH}$, et al. The ten-twenty electrode system of the International Federation. The International Federation of Clinical Neurophysiology. Electroencephalogr Clin Neurophysiol Suppl 1999;52:3-6.

37. Hallett M. Movement-related cortical potentials. Electromyogr Clin Neurophysiol 1994;34:5-13.

38. Shibasaki H, Barrett G, Halliday E, et al. Components of the movement-related cortical potential and their scalp topography. Electroencephalogr Clin Neurophysiol 1980;49:213-26.

39. Shibasaki $\mathrm{H}$, Hallett $\mathrm{M}$. What is the bereitschaftspotential? Clin Neurophysiol 2006;117:2341-56.

40. Kornhuber HH, Deecke L. Hirnpotentialaenderungen bei Willkuerbewegungen und passiven Bewegungen des Menschen: Bereitschaftspotential und reafferente Potentiale. Pflugers Arch Gesamte Physiol Menschen Tiere 1965;284:1-17.

41. Deecke L, Scheid P, Kornhuber H. Distribution of readiness potential, pre-motion positivity, and motor potential of the human cerebral cortex preceding voluntary finger movements. Exp Brain Res 1969;7:158-68.

42. Deecke L. Bereitschaftspotential as an indicator of movement preparation in supplementary motor area and motor cortex. Ciba Found Symp 1987;132:231-50.

43. Spring JN, Place N, Borrani F, et al. Movement-related cortical potential amplitude reduction after cycling exercise relates to the extent of neuromuscular fatigue. Front Hum Neurosci 2016;10:257.

44. Wright DJ, Holmes PS, Di Russo F, et al. Differences in cortical activity related to motor planning between experienced guitarists and non-musicians during guitar playing. Hum Mov Sci 2012;31:567-77.

45. Falvo M. Neurophysiological adaptations to resistance training and repetitive grasping. St Louis: Washington University, 2010.

46. Doppelmayr M, Finkenzeller T, Sauseng P. Frontal midline theta in the pre-shot phase of rifle shooting: differences between experts and novices. Neuropsychologia 2008;46:1463-7.

47. Gevins A. High-resolution EEG mapping of cortical activation related to working memory: effects of task difficulty, type of processing, and practice. Cereb Cortex 1997;7:374-85.

48. Sauseng P, Klimesch W, Schabus M, et al. Fronto-parietal EEG coherence in theta and upper alpha reflect central executive functions of working memory. Int J Psychophysiol 2005;57:97-103.

49. Pfurtscheller G, Lopes da Silva FH. Event-related EEG/MEG synchronization and desynchronization: basic principles. Clin Neurophysiol 1999;110:1842-57.

50. Pfurtscheller G, Andrew C. Event-Related changes of band power and coherence: methodology and interpretation. J Clin Neurophysiol 1999;16:512-9.

51. Cheng M-Y, Hung C-L, Huang C-J, et al. Expert-novice differences in SMR activity during dart throwing. Biol Psychol 2015;110:212-8.

52. Babiloni C, Carducci F, Cincotti F, et al. Human movement-related potentials vs desynchronization of EEG alpha rhythm: a highresolution EEG study. Neuroimage 1999;10:658-65.

53. Kaiser J, Birbaumer N, Lutzenberger W. Event-related beta desynchronization indicates timing of response selection in a delayed-response paradigm in humans. Neurosci Lett 2001;312:149-52.

54. Deiber M-P, Sallard E, Ludwig C, et al. EEG alpha activity reflects motor preparation rather than the mode of action selection. Front Integr Neurosci 2012;6:59.

55. Tzagarakis C, Ince NF, Leuthold AC, et al. Beta-band activity during motor planning reflects response uncertainty. $J$ Neurosci 2010:30:11270-7.
56. Zaepffel M, Trachel R, Kilavik BE, et al. Modulations of EEG beta power during planning and execution of grasping movements. PLOS One 2013;8:e60060.

57. Gudmundsson S, Runarsson TP, Sigurdsson S, et al. Reliability of quantitative EEG features. Clinical Neurophysiology 2007;118:2162-71.

58. Baumeister J, Reinecke K, Schubert M, et al. Effects of induced fatigue on brain activity during sensorimotor control. Eur J Appl Physiol 2012;112:2475-82.

59. Silva F, Arias-Carrión O, Teixeira S, et al. Functional coupling of sensorimotor and associative areas during a catching ball task: a qEEG coherence study. Int Arch Med 2012;5:9.

60. Roberts A, Fillmore P, Decker S. Clinical applicability of the testretest reliability of qEEG coherence. NeuroRegulation 2016;3:7-22.

61. Colby SM, Hintermeister RA, Torry MR, et al. Lower limb stability with ACL impairment. J Orthop Sports Phys Ther 1999;29:444-54. discussion 452-4.

62. Wikstrom EA, Tillman MD, Smith AN, et al. A new force-plate technology measure of dynamic postural stability: the dynamic postural stability index. J Athl Train 2005;40:305-9.

63. Jensen RL. 27 Conference of the International Society of Biomechanics in Sports Reliability of time to stabilization in single leg standing, $2009: 346-9$.

64. Palmieri RM, Ingersoll CD, Stone MB, et al. Center-of-pressure parameters used in the assessment of postural control. J Sport Rehabil 2002;11:51-66.

65. Fransz DP, Huurnink A, de Boode VA, et al. Time series of ground reaction forces following a single leg drop jump landing in elite youth soccer players consist of four distinct phases. Gait Posture 2016;50:137-44

66. Li Z, Liang YY, Wang L, et al. Reliability and validity of center of pressure measures for balance assessment in older adults. $J$ Phys Ther Sci 2016:28:1364-7.

67. Logerstedt D, Grindem H, Lynch A, et al. Single-legged hop tests as predictors of self-reported knee function after anterior cruciate ligament reconstruction. Am J Sports Med 2012;40:2348-56.

68. O'Connor ML. The development of the Single-Leg Landing Error Scoring System (SL-LESS) for lower extremity movement screening: theses and dissertations University of Wisconsin-Milwaukee, 2015.

69. Tombaugh T. Trail making test A and B: normative data stratified by age and education. Archives of Clinical Neuropsychology 2004;19:203-14.

70. Maruff $P$, Thomas E, Cysique L, et al. Validity of the CogState brief battery: relationship to standardized tests and sensitivity to cognitive impairment in mild traumatic brain injury, schizophrenia, and aids dementia complex. Archives of Clinical Neuropsychology 2009;24:165-78

71. Woods DL, Kishiyama MM, Yund EW, et al. Improving digit span assessment of short-term verbal memory. J Clin Exp Neuropsychol 2011;33:101-11.

72. PIETRZAK R, Maruff P, MAYES L, et al. An examination of the construct validity and factor structure of the Groton Maze Learning Test, a new measure of spatial working memory, learning efficiency, and error monitoring. Archives of Clinical Neuropsychology 2008;23:433-45.

73. Verbruggen F, Logan GD. Response inhibition in the stop-signal paradigm. Trends Cogn Sci 2008;12:418-24.

74. Van der Elst W, Van Boxtel MP, Van Breukelen GJ, et al. The Stroop color-word test: influence of age, sex, and education; and normative data for a large sample across the adult age range. Assessment 2006;13:62-79.

75. Lysholm J, Gillquist J. Evaluation of knee ligament surgery results with special emphasis on use of a scoring scale. Am J Sports Med 1982;10:150-4.

76. Rusu AC, Kreddig N, Hallner D, et al. Fear of movement/(Re)injury in low back pain: confirmatory validation of a German version of the Tampa Scale for Kinesiophobia. BMC Musculoskelet Disord 2014:15:280

77. Blais A-R, Weber EU. A Domain-Specific Risk-Taking (DOSPERT) Scale for Adult Populations. Judgment and Decision Making 2006;1 https://ssrn.com/abstract=1301089

78. Winkler I, Debener S, Müller K-R, et al. On the influence of high-pass filtering on ICA-based artifact reduction in EEG-ERP. Conf Proc IEEE Eng Med Biol Soc 2015;2015:4101-5.

79. Saliasi E, Geerligs L, Lorist MM, et al. The relationship between $\mathrm{p} 3$ amplitude and working memory performance differs in young and older adults. PLOS One 2013;8:e63701

80. Luchsinger $\mathrm{H}$, Sandbakk Øyvind, Schubert $\mathrm{M}$, et al. A comparison of frontal theta activity during shooting among biathletes and cross-country skiers before and after vigorous exercise. PLOS One 2016;11:e0150461. 
81. Bastos AM, Schoffelen JM. A Tutorial Review of Functional Connectivity Analysis Methods and Their Interpretational Pitfalls. Front Syst Neurosci 2015;9:175

82. Di Russo F, Bultrini A, Brunelli S, et al. Benefits of sports participation for executive function in disabled athletes. $J$ Neurotrauma 2010;27:2309-19.

83. Huijgen $\mathrm{BCH}$, Leemhuis $\mathrm{S}$, Kok NM, et al. Cognitive functions in elite and sub-elite youth soccer players aged 13 to 17 Years. PLoS One 2015;10:e0144580.

84. Verburgh L, Scherder EJA, van Lange PAM, et al. Executive functioning in highly talented soccer players. PLoS One 2014:9:e91254

85. Herman DC, Barth JT. Drop-Jump Landing Varies With Baseline Neurocognition: Implications for Anterior Cruciate Ligament Injury Risk and Prevention. Am J Sports Med 2016;44:2347-53.

86. Swanik CB, Covassin T, Stearne DJ, et al. The relationship between neurocognitive function and noncontact anterior cruciate ligament injuries. Am J Sports Med 2007;35:943-8.

87. Hutchison $M$, Comper $P$, Mainwaring $L$, et al. The influence of musculoskeletal injury on cognition: implications for concussion research. Am J Sports Med 2011;39:2331-7.
88. Mokha M, Wilkerson GB. Neurocognitive reaction time predicts lower extremity sprains and strains. International Journal of Athletic Therapy and Training 2012;17:4-9.

89. Mang CS, Clair JM, Collins DF. Neuromuscular electrical stimulation has a global effect on corticospinal excitability for leg muscles and a focused effect for hand muscles. Exp Brain Res 2011;209:355-63.

90. Hart JM, Kuenze CM, Pietrosimone BG, et al. Quadriceps function in anterior cruciate ligament-deficient knees exercising with transcutaneous electrical nerve stimulation and cryotherapy: a randomized controlled study. Clin Rehabil 2012;26:974-81.

91. Pietrosimone B, McLeod MM, Florea D, et al. Immediate increases in quadriceps corticomotor excitability during an electromyography biofeedback intervention. J Electromyogr Kinesiol 2015;25:316-22.

92. Gibbons CE, Pietrosimone BG, Hart JM, et al. Transcranial magnetic stimulation and volitional quadriceps activation. J Athl Train 2010;45:570-9.

93. Ireland ML. The female ACL: why is it more prone to injury? J Orthop 2016;13:A1-4.

94. Agel J, Arendt EA, Bershadsky B. Anterior cruciate ligament injury in national collegiate athletic association basketball and soccer: a 13year review. Am J Sports Med 2005;33:524-31. 